\title{
Regulatory support for the redevelopment design system
}

\author{
Azarii Lapidus ${ }^{1}$, and Dmitry Topchiy ${ }^{* 10000-0002-3697-9201]}$ \\ ${ }^{1}$ Moscow State University of Civil Engineering, 129337 Moscow, Russia
}

\begin{abstract}
One of the main features of construction as a branch of material production is a wide range of various types of regulations, technical, process flow and methodology documentation, and governing standards determining the conditions for development of design solutions and the formation of the functional quality of construction products. Regulatory control of practical activities in the field of construction should be considered as a necessary tool and most important means of achieving the planned results, bearing in mind, first of all, the quality of organizational and process solutions, methods of construction operations in the specific conditions of a construction site, methods of ensuring control and supervisory measures in simple and complex construction processes. The structure of city-forming factors had changed noticeably by the middle of the twentieth century: the number of people employed in the service sector, education, and the banking sector had grown. The industrial production and transport structure has changed. Society began to impose increasingly stringent requirements on sanitary standards for the functioning of industries and many of them were forced to close down. Science-intensive industries sprang up in major cities to employ the redundant workers. The share of the economically active population employed in scientific and design centers, and medical and educational institutions increased. Relocation of some enterprises outside the major cities in Europe coincided with the perceived need for their radical technical re-equipment. Our country was at least $50-70$ years late with these measures, which caused a general technical lag. Intensive housing construction in large cities of Russia has led to the fact that employees often use public and private transportation to get to work from "dormitory" areas in the direction of the center. As market principles for assessing the effectiveness of enterprises allowed for economic reforms, introduction of cadastral changed the structure of the urban economy.
\end{abstract}

Keywords. Renovation, re-profiling of urban areas, production organization, economic reform, redevelopment.

\section{Introduction}

The general scientific and technological progress and innovative development of modern technologies in the construction industry are aimed at a systemic result providing for an integral combination of requirements: increasing the level of the functional quality, reducing

${ }^{*}$ Corresponding author: 89161122142@mail.ru 
the level of the environmental load, minimizing the duration of construction, optimizing the duration and material costs for completed construction projects of various functional purposes and the level of responsibility. Regulatory support of construction operations is also undergoing a certain stage of development. Adequate and competent application of the existing provisions is certainly an important and invariably relevant resource necessary to achieve actual indicators of the functional quality of construction products. The structure (system) of regulatory documents in the construction industry is a set of legally formalized requirements (taking into account the functional, technological, legal, and operational characteristics of construction products) developed and approved by the competent (state) authorities for application in construction projects at all stages of their life cycle.

Structural simplicity, unambiguity, and clarity are the main advantages of a prescriptive building code. Compliance with the prescribed requirement forms the conditions for guaranteed achievement of a certain deliverable (completed construction project) with unconditional implementation of the prescribed rules for performance of technological (construction) processes, use of building materials, structures, mechanization facilities, as well as timely use of the established material and intangible resources. The obligation and/or necessity of following the prescriptions of the construction norms (more precisely, normative documentation) is determined by the history of development and the general level of the construction science, and the public demand for ensuring the functional quality of construction products. The choice of the optimization direction of requirements for the scope and content of the design documentation sections shall be implemented through a systematic and comparative analysis of similar requirements to the scope and content of the design documentation given in the domestic construction codes, which regulated this issue at the earlier stages of the formation of the construction industry industrial period of development. The genesis of domestic experience and the formation stages of regulatory documentation in the field of construction can be analyzed on a historical scale, starting with the period of industrialization in late XIX-early XX centuries. Intensive growth of industry was accompanied by a dynamic rate of development, in accordance with the level of development of the material base and scientific knowledge of the territories of construction projects for various functional purposes. In the absolute majority of cases, the necessary design solutions had a minimum amount of documentation, one or two sheets of the graphic part and a small amount of explanatory note required to be presented as the approval package for architectural, design, technological, organizational and management decisions. It can also be noted that design, architectural, calculation and structural, and organizational and process solutions were developed by the same specialist (in a vast majority of cases by the architect) and they showed the subjective ideas of the project author about the functional features and methods of implementing design solutions. The issues and tasks tackled by the architects included, among others, cost estimations, search for suppliers of building materials, hardware, and structures, and field supervision. Practical implementation of the strategy of intensive development of accessible territory in the Soviet Union in the $1920-1940^{\mathrm{s}}$ determined the need to attract various industry authorities, and people's commissariats to develop individual departmental rules for organizing industry-based construction operations. Centralized state regulation in the development of building codes and rules for construction operations including issues related to the support of organizational and process design of construction, was practically absent until the middle of the XX century. In the mid-sixties of the XX century, the first instruction was developed on the design, scope and content of documentation for construction facilities, buildings and structures of various functional purposes. The regulatory document «System of Design Documentation in Construction» (SDDC) which was developed in 1979 regulated the format of unification and standardization of requirements and rules for construction drawings and other types of design documentation. 


\section{Materials and methods}

Redevelopment of the urban environment plays a major role in the effective development of any metropolis. The main trends in the redevelopment of urban clusters are two vectors. The first one involves significant changes in the environment without changing the functional purpose of the territory under consideration, while the second vector provides for a qualitative change in the structure of the functioning of a part of the urban area.

Re-profiling of industrial areas is one of the most common methods of redevelopment of urban clusters involving a change in the functional purpose of the territory. Adapting industrial buildings to civil needs is the most affordable way to solve the problem of parkand-rides, garages, shopping centers, and a number of other social facilities. Research and development in this area was carried out for several years by specialists of many institutes and firms. A special role is given to research on the impact of the reconstruction processes of underground parts (strengthening of foundations, increasing underground space) and process solutions for works aimed at the preservation of adjacent buildings.

The historical period corresponding to the late XX-early XXI centuries is considered a post-industrial period of development. The domestic experience of regulation in the field of construction is characterized by a consistent transformation of regulatory documents: the end of Soviet era $\rightarrow$ the transition period $\rightarrow$ the formation of signs of a market economy and state capitalism. It can be noted that the development and improvement of the regulatory framework in construction is accompanied by the corresponding modification of the rules for design documentation, design estimates, detailed designs, graphics, and explanatory notes. The uniqueness of the considered building codes was in the principles of the approach to the preparation of design documentation.

The principles were not reflected in the modern requirements for the composition of the sections and the content of project documentation.

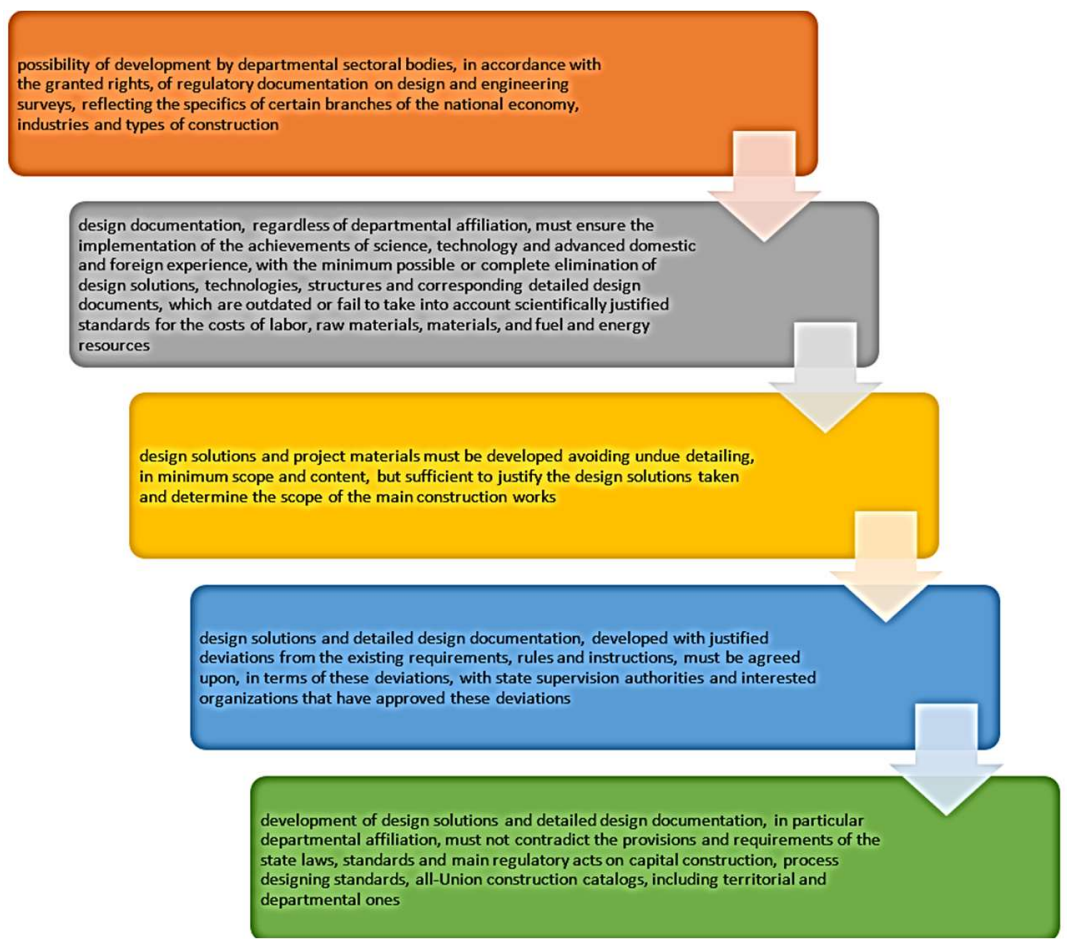

Fig. 1. Structure of the formation of design solutions at redevelopment sites. 
The above development principles of design solutions and detailed design documentation include the need to apply and actively implement modern efficient technical solutions, technologies, materials, structures and equipment in the field of construction, and the possibility of using national standards and building requirements in the design provided that the scope of design documentation is minimized. It can be noted that excessive requirements for design documentation contribute to the emergence of administrative barriers and an increase in time, financial, and human resources, necessary for the development of design documentation and its expertise. For example, the excessively large number of sections and subsections of the project documentation can lead to the involvement of multiple subcontracting design organizations, which negatively affects the quality of project documentation as a whole, due to the lack of conditions for coordination of actions of subcontractors.

Particulars of the choice of design and format of the construction system are influenced by various factors affecting the construction project, which can be divided into two groups: internal and external. Functional and technological, and structural and compositional features of the designed construction project belong to the conditional group of internal factors.

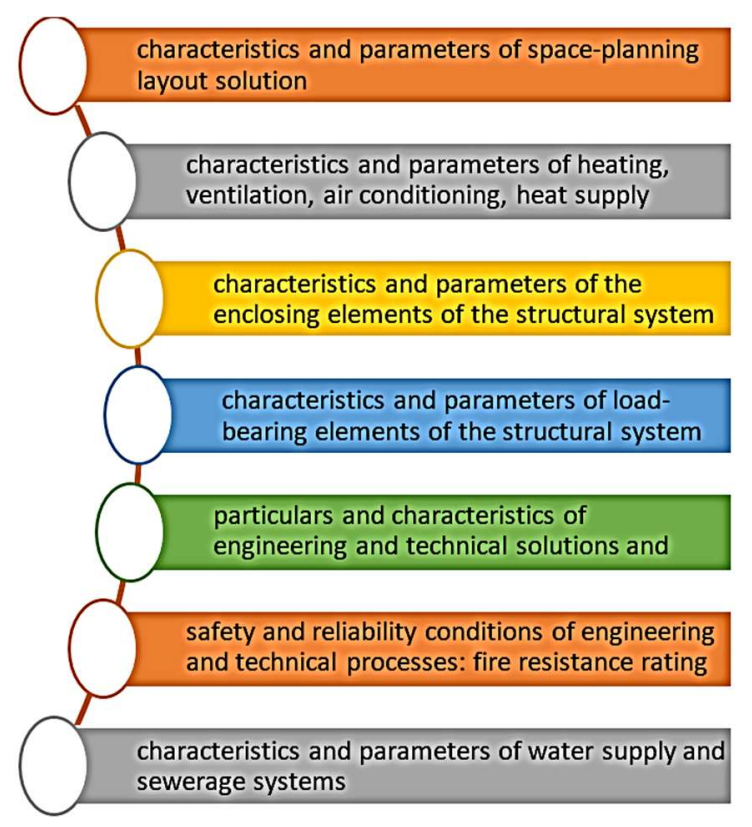

Fig. 2. Organizational and technical factors of redevelopment design.

The generalized and conditional factors shown above characterize the processes featured in a construction project. Review of the tasks associated with a particular construction project may include other issues, which are specific for this particular functional and engineering, for example: airtightness of industrial and residential premises; lightning protection; consideration of special loads and impacts. The composition and parameters of the functional and engineering features of the construction project are crucial, mainly for industrial buildings and structures (new construction; reconstruction; expansion; technical modernization). The natural environment surrounding the designed capital construction project has a direct and immediate impact on the nature and possibilities of the established sequence of construction works and processes. Environmental factors affecting the particulars of the composition and indicators of the construction organization plan and the quality of formation of the construction system belong to the conditional group of external factors. 


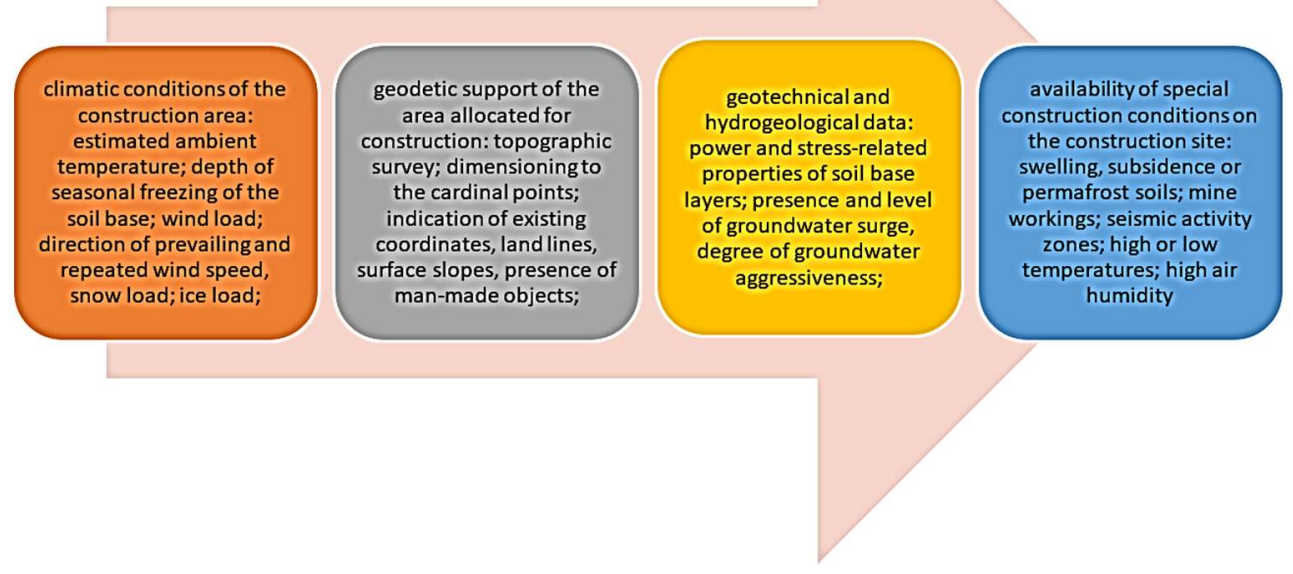

Fig. 3. External organizational and technical factors influencing the formation of process documentation for renovation objects.

\section{Results and discussion}

Environmental factors and natural climatic impacts should be duly accounted for in the CMP by increasing the duration of technological works and processes or introducing additional technological breaks therein in accordance with the requirements of the relevant regulatory documents. For example, during the season characterized by persistent sub-zero air temperatures, the soil base layers intended for earthworks and the arrangement of foundations of construction projects get frozen. Frost penetration considerably increases the abrasion of steel working parts of construction machines and mechanisms by the soil in excavation works. Depending on the type of excavation machinery, soils and technological processes, the wear intensity of working parts in frozen soils may exceed a similar indicator for nonfrozen soils by 50-700 times.

\section{Conclusion}

Thus, today there is no regulatory structure ensuring technical safety in the design and construction of renovation projects. It is advisable to consider the possibility of adjusting the requirements for the composition of design documentation for renovation projects; to take into account particular features of redevelopment and renovation activities when amending SP 48.13330.2019 «Construction Organization», in particular the requirements for the development of construction management plans (CMP) and operations management plans (OMP).

\section{References}

1. A.A. Yashmanova, A.S. Efremenko. Improvement of the earthwork technology based on the optimization of the set of machines, Youth Herald of the Irkutsk National Research Technical University 8 3, (2018). 
2. D.V. Topchiy, S.G. Muzychenko, S.D. Gotsoev. Formation of a structure for calculating the effectiveness of organizing control of organizational and technical processes in reprofiling, Eurasian Science Bulletin 11 5, 72 (2019).

3. D.V. Topchiy. Preparation of former industrial sites for civil construction, Technology and organization of construction operations 4, 34-41 (2014).

4. P.P. Oleinik. Organization of construction operations: monograph. M.: ASV Publishers, $576(2010)$.

5. V.V. Molodin, E.N. Likhachev. Evolution of architectural and construction solutions for industrial buildings in Novosibirsk, Polzunovskiy Herald 4-1, 123-127 (2013).

6. V.V. Molodin, B.S. Mosakov, V.L. Kurbatov. Technology of erection of buildings and structures. Novosibirsk, (2013).

7. V.V. Molodin, S.V. Volkov. Organizational and technical design of residential construction, Learning guide NSUACE (Sibstrin). Novosibirsk, (2015).

8. P.S. Lufkin, A. Desai, J. Janke. Estimating the Restoration and Modernization Costs of Infrastructure and Facilities, Public Works Management and Policy 10, 40-52 (2005).

9. R.A. Lundin, A. Söderholm. Theory of the Temporary Organization, Scandinavian Journal of Management 11(4), 437-455 (1995).

10. J. Maleyeff. Exploration of Internal Service Systems Using Lean Principles, Management Decision 44 (5), 674-689 (2006).

11. L.J. Menor, A.V. Roth. New Service Development Competence in Retail Banking: Construct Development and Measurement Validation, Journal of Operations Management 25 (4), 825-846 (2007). 